\title{
Intergenerational differences of CSR activities in family-run businesses in eastern Thailand
}

\author{
Sapanna Laysiriroj@ and Walter Wehrmeyer
}

\author{
* Correspondence: w.wehrmeyer@ \\ surrey.ac.uk \\ Centre for Environment and \\ Sustainability, University of Surrey, \\ Arthur C Clarke building, Floor 2 \\ Guildford, UK
}

\begin{abstract}
This paper looks at differences and similarities in CSR between generations of familyrun businesses in Thailand, especially their motivation, behaviour, targets, activities, and expectations towards CSR. It will be argued that family-run businesses in Thailand practise CSR informally, driven by a mentality of "giving back to society" and mostly influenced by religion and culture. Family-run businesses generally approach CSR differently from larger corporations. This paper also discusses differences of priorities between 1st and 2nd generation owners, with 1st generation FRBs tend to focus on survival and growth, while the 2nd generation on profit. Despite struggling to survive, 1st generation family-run businesses are typically engaged in CSR activities which influences the 2 nd generation to follow suit.
\end{abstract}

Keywords: Family-run businesses, Intrinsic CSR, CSR activities, Intergenerational, CSR differences

\section{Background}

Corporate social responsibility (CSR) and family-run business (FRB) research have been, separately, studied academically for many decades. This research intends to bridge these 2 topics together by looking at CSR in perspectives of FRBs, here defined as "A business where the owner and/or top-manager is a descendant of, and is supported by, commitment from founder and other family members, fully manage and control the company's operation and vision with sense of psychological ownership". This definition shares the properties of some existing definitions by other scholars (Ward, 1987; Astrachan \& Shanker, 2003; Chua et al., 1999; Astrachan, 2002; Chrisman et al., 2005) and it is suitable to describe the type of FRBs this research is focusing on.

Many companies in Asia do not understand CSR in the Western way but recognise corporate philanthropy and developing the local community as activities commensurate with CSR (Uriarte, 2008). In Asian countries, CSR is closely related to matters of the local community, historical events, and countrywide cultural traditions which forms diverse CSR activities around Asia (Chapple \& Moon, 2005). They also state that CSR in forms of socially responsible products and processes, and socially responsible employee engagement can be seen across Asia although the most established form of CSR involves traditional community involvement. Therefore, in Asia, a growing number of companies describe CSR as social and environmental effectiveness of their firms.

(c) The Author(s). 2020 Open Access This article is distributed under the terms of the Creative Commons Attribution 4.0 International License (http://creativecommons.org/licenses/by/4.0/), which permits unrestricted use, distribution, and reproduction in any medium, provided you give appropriate credit to the original author(s) and the source, provide a link to the Creative Commons license, and indicate if changes were made. 
Nevertheless, very few FRBs, especially in Thailand, have used the term CSR when describing such activities (Onozawa, 2013; Laysiriroj et al., 2017). This research will discover and define what CSR activities are being carried out by Thai FRBs and how CSR practices may differ between 1st and 2nd generation FRBs. Before that, the origin of CSR values needs to be explored which could help identify and understand motives behind CSR activities in family business.

\section{COPERATE social responsibility concept}

The concept of CSR has developed over time depending on its purpose so there is no singular definition that is universally accepted (Dahlsrud, 2008; Brammer et al., 2007). Initially, CSR was said to have economic value to companies where it fits with profit maximisation (Friedman, 2009). Jenkins (2004) stated that businesses' social responsibility began by basing on philanthropic donations and activities of large companies so actions such as endowing universities and establishing worker model communities are generally results of these large and wealthy companies. Subsequently, CSR has been applied to address ethical standards for society and a company's stakeholders. Carroll (1979) mentioned that CSR has expanded to cover economic, legal, ethical, and philanthropic aspects. Ever since, scholars started to relate CSR to the stakeholder concept (Carroll, 1991; Freeman, 2010 p. 38) which takes employees, suppliers, the community and the surrounding society into account (Sims and Keon, 1997; Zaharia, 2011; Euaanant et al., 2011; Lee et al., 2013).

Broadly, an organisation culture is often defined as the shared values in an organisation. Jamali \& Mirshak (2007) mentioned that differences in culture affects CSR dynamics within companies. This was supported by Perrini \& Minoja (2008) who studied CSR in Italian medium-sized FRBs and found out that owner's beliefs and moral values, and past experiences, influence CSR strategies of the company. In addition, Lantos (2001) suggested that businesses may engage in activities that are expected by local communities and may not necessarily be limited to legal standards such as respecting people, avoiding social danger, and preventing injuries to surrounding people which often coincide with religious values. Carroll (1979) added that identifying these activities may be difficult because they are not formally documented, and they are generally difficult to measure. Evidently, differences in culture affect CSR dynamics within companies (Jamali \& Mirshak, 2007).

It appears that local corporations primarily emphasise on the importance of meeting their responsibilities and obligations towards their employees and customers. Many researchers are focused on government policies of developing countries which includes environmental matters, corruptions issues, employment issues, regulation issues, and poverty education etc. (Visser, 2008; Dobers \& Halme, 2009). However, there is research on CSR practices adopting firm level (MNCs, Large enterprises, SMEs, Family business) in many fields such as employee relations and retention, commitment on CSR, community involvement, and stakeholder relationship (Carroll, 1979; Chapple \& Moon, 2005; Jamali et al., 2009; Jenkins, 2004; Looser \& Wehrmeyer, 2016).

However, CSR practices vary substantially between different sizes of organisation. Jamali et al. (2009) illustrates clear differences in orientations between CSR of SMEs and MNCs and concluded that SMEs are typically flexible and prosper through the 
motivation driven by their founders and some forms of innovation from being flexible. It should be noted that most FRBs are SMEs, but not every SMEs are FRBs.

However, given the overlap in the absence of papers discussing specifically about FRBs and CSR, information on SMEs may be used as a proxy to represent FRBs. Therefore, it is valuable to investigate CSR in FRB perspective since this area is still limited. This paper will contribute the basis of empirical results that identify similarities and differences between CSR of 1st and 2nd generation FRBs in Thailand in four aspects: (1) CSR Drivers (2) CSR Behaviour (3) CSR Target and Activities (4) Expectations from CSR.

\section{Methodology}

The purpose of this research is to examine how the perspective of CSR activities differ across different generations of FRB owners in Thailand. Since CSR in Thai FRBs research is very narrow, there is limited comparable resources for further development in the area. Therefore, this research is exploratory and extends different findings of previous research which were more focused on FRBs in general such as FRB succession and relationship between founders and successors.

\section{Data collection and analysis}

The data gathering method had to be semi-structured interview because it provides indepth observation and provide wider perspective from FRB owners' experience. Since this research is not explanatory and normative or confirmatory, hypothesis testing is not suitable for this research because of the nature of the research and the nature of the knowledge sought (Mackey \& Gass, 2005).

Pilots had been conducted with two FRB owners to test the reliability and suitability of the interview questions. To address ethical concerns, the researcher followed ethical principles of the University of Surrey including the assurance of full confidentiality of the results and the participating companies. Using snowball sampling, a total of 28 FRBs in Eastern Thailand of various sizes had been selected and were owned by 17 FRB owners comprising of 7 founders (1st generation) and 10 (2nd generation) successors in Eastern Thailand, from 3 different business sectors; hotel, fruit processing, and jewellery.

The interviews contained five sections namely (1) Demographic and historical information (2) Exploring the idea of CSR or main drivers of CSR activities (3) Determining the views and aspect of CSR activities of the FRB owners (4) Determining the receiver of CSR activities (5) Determining owners' expectations from CSR activities in FRBs.

In this case, interviews are less formal and can grasp answers with higher depth and sincerity. Moran (2006) suggested that spontaneous answers of respondents in a conversation can allow a more truthful responses than formal interviews. Each interview session lasted between 1 to $2 \mathrm{~h}$ and was recorded (permitted by the interviewees). All recorded conversations were transcribed for better evaluation and understanding (Saunders et al. 2009). After which, 2D and 3D, Thematic Analysis had been used to organise, analyse and to produce themes and subsequent main-themes and sub-themes, in line with previous efforts (Aronson, 1995; Vaismoradi et al., 2013). These themes were then evaluated into new homogeneous groups. 


\section{Results: FRB owners information}

This section discusses differences in CSR perceptions between the 1st and 2nd generations of Thai FRB owners. Table 1 shows the broad distribution of comapnies by 1st or 2nd generation and size.

There are 11 female owners and 6 male owners. All, except for 2 female interviewees, are Buddhists. In general, 1st generation most owners have significantly lower education level (up to elementary school and high school in Thailand) while 2nd generation owners often have higher education level (bachelor and postgraduate degrees abroad). 1st generation owners are also generally a lot older than 2nd generation owners. From the 17 interviewees, 4 owners are from the jewellery sector, 4 are from fruit-processing sector, and 9 are from the hotel sector. Company sizes in the hotel sector are mixed and some owners run more than 1 hotels. The hotel sector includes 1 micro-small size hotel which is run by a 2nd generation owner, 6 small hotels, 5 owned by the 1st generation owners and 5 owned by the 2 nd generation. Out of 12, 10 medium sized hotels are owned by 1 st generation themselves and 2 are owned by the 2 nd generation. The only large company in the sample is in the hotel sector, currently run by both generations. There are 4 small companies in the fruit processing sector in the sample, 2 of which are run by 1 st generation owners and 2 by the 2nd generation. Lastly, the sample includes 1 owner from microsmall company and 3 owners from small sized companies in the jewellery sector.

\section{Intergenerational differences in CSR in THAI family-run business}

From the interviewed data, founders and successors show both similarities and differences in CSR motivation and practices and CSR target and expectation from FRB owners' perspective. The results can be divided into four parts (1) The motives for conducting CSR activities (2) CSR Behaviour (3) CSR targets and activities (4) Expectations from CSR activities practiced:

\section{CSR motives among Thai FRB owners}

According to Table 2, the interviewees suggested that the origin of CSR values in FRB owner's perspective are religion, family-culture, and owner's ethical values. Both founders and successors have similar motives to conduct CSR which are internal and intrinsic.

Furthermore, Table 2 shows that the 1st generation tend to have a much more limited conceptualisation of CSR and refer to CSR activities as TV commercial that large

Table 1 FRB Owners Information

\begin{tabular}{llll}
\hline $\begin{array}{l}\text { FRB Owners } \\
\text { Information }\end{array}$ & Total & 1st Generation (person) & 2nd Generation (person) \\
\hline $\begin{array}{l}\text { Number of FRB } \\
\text { owners }\end{array}$ & 17 & 7 & 10 \\
Company Size & Total & $\begin{array}{l}\text { Number of Firms owned by 1st } \\
\text { Generation (firms) }\end{array}$ & $\begin{array}{l}\text { Number of Firms owned by 2nd } \\
\text { Generation (firms) }\end{array}$ \\
Large & 1 & 0 & 1 \\
Medium & 12 & 2 & 10 \\
Small & 13 & 6 & 7 \\
Micro Small & 2 & 1 & 1 \\
Total & 28 & 9 & 19 \\
\hline
\end{tabular}


Table 2 CSR in Thai family-run business between 1st and 2nd generation

\begin{tabular}{|c|c|c|c|}
\hline \multicolumn{2}{|l|}{ CSR Dimension } & 1st Generation & 2nd Generation \\
\hline \multicolumn{4}{|l|}{ Part 1: CSR Driver } \\
\hline \multirow[t]{3}{*}{ Origin of Values } & Religion & Very high & Low \\
\hline & Family-Culture & No & High \\
\hline & Personal Ethical Values & High & High \\
\hline \multicolumn{4}{|c|}{ Part 2: CSR Behaviour } \\
\hline \multirow[t]{7}{*}{ Dimensions } & Formalisation & Very Little & Quite High \\
\hline & Link to Business & Very Little & High \\
\hline & Management Style & Paternalistic & Business Model \\
\hline & Motivation & Ethics & Profit \\
\hline & Consistency & One-offs & Systematic \\
\hline & System & Informal & Procedural \\
\hline & Reason & Personal Satisfaction & Business Purpose \\
\hline \multicolumn{4}{|c|}{ Part 3: Target and Activities } \\
\hline \multirow[t]{5}{*}{ Employees } & Concern & Income & Employee Productive \\
\hline & Reward System & Money & Commissions \\
\hline & Communication & Person-person & Agenda Meeting \\
\hline & Rules & Flexible & Procedural \\
\hline & Basic Needs & High & High \\
\hline \multirow[t]{6}{*}{ Social } & Concern & Personally Justified & Economically Justified \\
\hline & Branding & Family's Name & Business reputation \\
\hline & Religious Activities & High & Low \\
\hline & Social Sponsorship & Lower & High \\
\hline & Government needs & High & High \\
\hline & Join Social Organisation & Yes & Yes \\
\hline \multirow[t]{3}{*}{ Environment } & Concern & No mention & Yes \\
\hline & Waste & No mention & Reuse, Reduce and Recycle \\
\hline & Natural concern & No mention & Sponsorship \\
\hline \multicolumn{4}{|c|}{ Part 4: FRB Owners Expectations } \\
\hline \multirow[t]{4}{*}{ Employees } & Employee Capability & Work Hard & Work Smart \\
\hline & Trust & Family Trust & Commitment Trust \\
\hline & Loyalty & To Owners & To Company \\
\hline & Employee's Satisfaction & Yes & Yes \\
\hline \multirow[t]{3}{*}{ Society } & Connections & Personal & Business \\
\hline & Social Benefits & Access to Resources & Brand Recognition \\
\hline & Be Part of Society & Yes & Yes \\
\hline \multirow[t]{3}{*}{ Business } & Customer's Trust Focus & Trust the Owners & Trust the Brand \\
\hline & Brand Image and Reputations & No mention & Yes \\
\hline & Competitive Advantage & No mention & Yes \\
\hline
\end{tabular}

companies and MNCs promote themselves. All 1st generation FRB owners stated that once their businesses are stable in the market, they want to return the benefits to their society because it is the society's support that have made them successful. 1st generation owners also believe in thanking their employees for their hard work. Therefore, employees are often treated like family members under the ownership of 1st generation owners. 
"I grew from almost nothing. Everything I have here was earned through hard work and endurance. I build my business like building a family because I want everyone to be close and help with one another, especially during hard times. So, I love and treat my employees like family. When I get to prosper, my family will also be better off - that includes everyone in the business as well."

On the other hand, 2nd generation owners appear to have better idea of CSR, due to higher education levels. Nonetheless, 2nd generation owners engage in intrinsic CSR because it provides personal satisfaction. They even chose to refer to these actions as "providing social benefits" rather than CSR because they believe that companies deliberately get involved in CSR to boost their brand image. Most of these owners feel that CSR imposes a hidden agenda towards marketing purposes and does not illustrate their willingness to give to society well enough.

"I think I understand how Westerners apply CSR in their business. It seems commercial to me and I do not really like it. I get involved with CSR to help people around me so that I feel good doing so. I think this is how I was brought up by my family since they are very caring for everyone."

This fundamental idea suggests that the roots of their CSR values are rather similar and that these roots are not based on extrinsic "Western" CSR, but on culture, ethics and attitudes. In general, both generations appear to be highly influenced by personal ethical values with regards to their CSR driver. This is evident in their honest belief in doing good for their employees and surrounding society. However, 1st generation owners are highly influenced by values they draw from their religion, while values of the 2nd generation originated from their family upbringing and culture.

For instance, 1st generation owners stated that Buddhist practices have strong influence to the ethical activities that they have implemented to their surrounding people. They believe in the Buddhist "Law of Karma". Inferences are made that good deeds will reap good results for the present and the future. In this manner, Buddhist teachings influence 1st generation owners to provide betterment to society so that they can have positive effects in return.

However, results also show that family culture is the main factor for the 2nd generation to engage in CSR. The 2nd generation are exposed to the practices initiated by the 1st generations so they absorb the culture of giving to society. This kind of exposure is more meaningful and relevant for them than religious teachings. On top of that, most 2nd generation owners are able to point out managerial errors of their parents, including CSR choices. Thus, the differences in CSR behaviours are what the 2nd generation believe are improvements over the 1st generations. Therefore, for FRB owners in Thailand, ethics is shaped by religion and culture, and less likely by the difference of their generation or age. It is also less likely that education levels affect how ethics are shaped by the owners.

\section{CSR Behaviours in Thai FRBs}

According to Table 2, CSR behaviours either differ when it comes to formalisation of CSR, linking of CSR to business, CSR management styles, CSR motivation, consistency of CSR practices, CSR system, or reasons for CSR engagement between 1st and 2nd generation. 
The results suggest that 1st generation FRB owners' management style is typically paternalistic, meaning that the owners act as parents to their employees and they work within closer proximity with their employees. For instance, training and personal development is done personally by them and when employees have personal problems such as shortage of money, health problems, and family member issues, the owner often help their employees financially or in kind. This is evident in the quote below:

"I am usually with my staff members on working days. It has always been this way. I have to look at how my people work, what they are doing wrong and how I can help them in their lives. When they have problems, I usually let them solve the problems by themselves but most of the time they are short of cash so I would lend them some money for them to fix their problems but most of the time I don't really expect the money to be returned."

In addition, 1st generation owners are much more informal because they do not really know what formal CSR is. In contrast, 2nd generation owners run their businesses much more as a mainstream business. They act as boss and friend to their employees yet introduce hierarchy systems into the business. Job descriptions are clearer under the governance of 2nd generation owners. Moreover, they treat employees differently according to their ranks: With managers, 2nd generation owners act more like friends while they make clear distinction as a boss to shop-floor staff. This is usually due to the job description where the managers are responsible for managing their subordinates. This, however, does not mean that they are not also humble owners. The quote explains why 2nd generation owners take this approach.

"As my company grows, it is impossible to take care of all my employees personally. So I spend more time with the heads of department and press on that they are to look after their people. I even give them the power to fire or hire particular people as they see fit."

Under 1st generation owners, employees follow orders of the owner while 2nd generation owners expect their employees to follow the rules and to be able to work without the owners being near. This created distance between 2nd generation owners and their staff but also shows more formalised business and CSR structure.

1st generation owners engage in CSR solely for personal ethical reasons while 2nd generation owners incorporate some business purposes into CSR engagement. These intrinsic CSR activities are done by 1st generation owners because they genuinely want to give back to society because the belief in "Law of Karma" allowed them to be happy when these activities take place.

However, 2nd generation owners have multiple motivations when engaging in CSR. They are both willing to help others but accept that these activities can benefit their businesses as well. 2nd generation owners mentioned that these ethical practices are good tools to motivate staff and improve employee productivity because they help to build strong relationships within the company. Intrinsic CSR activities also create good impressions of the company in the neighbourhood and so the company's image can be enhanced, although this may not be the dominant rationale.

"I see my parents give back to society, so I do it too. However, I will do these charitable events under the name of the company. A lot of the time, doing so creates business connections and also give us a good image in the neighbourhood."

Overall, CSR between the 1st and 2nd generation have clear distinctions. The 1st generation have a more paternalistic management style and informal CSR system. They 
also conduct CSR in simple often one-off ways which satisfy this personal ethics and some of community responsibility. In contrast, 2nd generation FRBs are more systematic in CSR practices and management. Their CSR activities are not only personal but are conducted to generate business benefits as well. From 1st to 2nd generation, the organisation structure changes (Greiner 1997) from flat-management to hierarchymanagement resulting in changes in CSR behaviours which affects the style and frequency of staff interaction.

\section{Differences and similarities in CSR target and activities}

Both generations' main targets are their employees and their surrounding society, in that order. The main difference is that 1st generation owners typically do not concern themselves with environmental issues while 2nd generation owners do to a small extent. Apart from the environment, other CSR targets, employees and society, are similar but their CSR practices differ.

\section{Employees}

All owners gave priority to their employees when considering CSR activities. However, both generations have different concerns for their employees and this has resulted in different CSR practices in terms of reward systems, communications, rules, and company events. There are also some aspects of the 1st generation that was adopted by the 2nd generation such as providing basic needs (food and shelter) for their employees. Because 1st generation owners think that money is the main motivation for their workers, they focus on providing financial aid to their employees at important times.

"It is very natural and quite often that my staff are facing financial problems. They could be in debt, or whether their family members are ill, and they cannot cover these expenses since many of them don't have savings. I can't turn a blind eye on these situations and so I would help them by lending them the money without expecting it to be returned."

When employees need extra cash, 1st generation owners lend a helping hand which creates the sense of being looked after to employees. This instills loyalty that grew from gratitude. In contrast, 2nd generation owners focus on activities that help to train their employees because they believe in personal development and productivity. Their reward system revolves around commission payment in order to motivate their staff to work more effectively. These commitments can help to reduce staff turnover rate for the companies.

Under 1st generation owners' governance, rules and regulations are more flexible because the companies are often less formalised, and they work more closely with their employees. When working within close proximity, flexibility is needed to help smoothen the relationship and workflow. Moreover, when issues arise, the owner themselves are able to make instant decision. However, being flexible can also play a part in causing bias in judgements because there is no standardised policy for decision making.

In contrast, 2nd generation owners state that they require standardised protocols to manage their employees because they work in a hierarchical system where there are relationships between owners and their subordinates. 
"I am not personally strict towards my employees. However, there has to be a proper system to monitor my staff behaviour. If they are ill, they can fill in sick leave forms and take their leave. This sort of system is important when dealing with people because it feels fair when everyone has to do it."

Therefore, formalised meetings arise from the need for a more formalised structure as the organisation grows but are needed to attempt to solve problems in a uniform manner. When decisions are made, a standardised protocol is created and so all employees are treated equally which results in a less biased working environment. However, due to this relationship gap between owners and shop-floor workers, a lack of personal bonds can remove the sense of loyalty from lower-ranked workers.

\section{Society}

CSR activities catered to surrounding society are clearly distinguished between 1st and 2nd generation owners. When 1st generation owners engage in CSR activities for societal benefits, they do so for personal justification and feel satisfied when the community recognises their face and name. They do have concerns for their business image but not while they conduct these societal activities. Therefore, 1st generation owners promote their family name when active in charitable events and sometimes use their own image doing sponsorship activities. The quote below a typical response from a 1st generation owner in this matter:

"Philanthropic activities should be done from the heart and that is what I am doing. These good deeds that we do will bring us good luck and fortune. That is why I have to specify my family name when these activities are held so that good deeds will be returned to us."

Conversely, 2nd generation owners are more focused on business because they would prefer for the community to recognise their business instead of themselves. Thus, when they do sponsorship activities and charity, they often promote their companies.

It can also be argued that 2nd generation owners engage in CSR in this manner because of the competition they are facing. The fact that their education level is higher, and their competitors are also more educated, FRB owners are required to be more competitive. Nonetheless, it is clear that only the 2nd generation are keen to incorporate CSR activities with their business management and structures.

"All our philanthropic activities come from our personal feelings. We want to do them for societal betterment. However, we cannot deny that these events incur costs. Since we are already doing it for society, why not project our brand image a little so that we can kill two birds with one stone?"

2nd generation owners have suggested that their parents have already created a good reputation for themselves. However, for a business to last in the long-run, it is necessary to enhance its reputation, recognising that every 1st generation business will sooner or later transform into a 2nd generation or something else.

Further difference is that the most common activity done by the 1st generation are religious based activities while 2nd generation owners focus on social sponsorship because these types of activities can be promoted to attract more attention from surrounding society. 1st generation often, for their personal fulfilment, provide support towards Buddhist ceremonies and religious establishment in terms of money and 
necessities. On the other hand, 2nd generation owners expect multiple benefits from their CSR activities. They stated that showing themselves as part of the community is key to grab attention and be recognised by the community. Doing so generates positive attitudes towards the business and allow them to be more competitive in the market. Some of these CSR activities are; blood donation, city cleaning event, charitable and philanthropic activities.

"Apart from genuinely helping our society, the company's image can also be improved. These activities are memorable to people and we want to be remembered and be the first company that people think of."

Both generation of owners join established social organisations such as the Rotary Club or the Lions in order to support bigger charitable projects. Benefits of joining these clubs are that their social statuses are improved and that the club can foster personal and business connections.

"We have been an associate with Rotary Thailand for a very long time. The club allows us to be part of big charitable events and also bring people together. A lot of business connections are made through club members."

Both generation of owners also stated that they are willing to provide financial help when required by local authorities to organise social events. Doing so will help foster connection with the authorities which provides a competitive edge for their companies and possibly attaining these people as customers. While 1st generation owners fully engage in CSR for intrinsic purposes to improve society for personal satisfaction, 2nd generation owners can appear to be more business oriented when engaging CSR. However, 2nd generation owners' CSR engagement is also intrinsic because there is a stronger influence from their family culture to engage in CSR. Without these family influences, they may not be engaging in CSR.

\section{Environment}

In the past decades, environment as a concern has grown in importance for MNCs, large enterprises and SMEs (Davis \& Frederick, 1984; Dahlsrud, 2008). However, FRBs are often less concerned about their environmental responsibility - in fact, none of the 1st generation owners have policies to save the environment, but the interviews found that activities pertaining to environment are amongst the activities that they personally refer to as CSR activities rather than "giving back to society".

"Dealing with environmental issues is difficult and it does not affect our society directly or instantly."

Out of all the interviews, only 2 participants, both 2nd generation owners, stated that they are engaging in activities that address the environment. For instance, a 2nd generation of FRB owner from the fruit processing sector stated that.

"I am active in waste management from fruit waste and waste from the production process. I reuse and recycle fruit wastes by producing organic fertilizer and animal food to generate another revenue source for the business."

In other words, the business only engages in environmental activities because it is financially beneficial to the business and most do not engage at all. The interviewees claimed that they are not emphasising on environmental concerns because, in their understanding, these activities require high amount of financial support and are time 
consuming. They suggested that the government and larger companies such as MNCs should be the ones tackling these issues.

Moreover, FRB owners also suggested that they would rather support activities that they believe will give them more satisfaction or directly impact their brand reputation whereas tackling environmental issues do not provide them with these benefits.

Overall, 1st generation owners have a personal motivation towards CSR. This motivation is religious based and that has brought about CSR that contains religious perspectives, in terms of Karma. That has driven them to promote social wellbeing that focuses on expanding the religion but, at the same time, excluding environmental issues due to lack of interest. 2nd generation owners have a more structured, pro-business perception towards CSR. They imply that CSR needs to benefit their businesses to keep up with competition. They follow the idea of "Western CSR" much closer and they often have a much more structured, formalised approach to CSR.

\section{Differences in expectations from CSR activities}

Different CSR activities also trigger expectations as most are not completely altruistic. The expectations by owners are discussed below, separated by stakeholder group, namely employees, society at large and their business.

\section{Employees}

Differences in expectations of employees are observed in terms of skills, loyalty, and trust. While both generations work towards creating employee satisfaction, 1st generation expects employees to be hard working (be diligent and strictly follow orders, be helpful to colleagues, and be able to multitask). They also want employees to have family-like trust from the informal work environment and relationship, especially when the employers and employees work together in close proximity:

"I want my employees to be loyal and hardworking. They should feel that I am family as I see them that way. Also, it is good when my employees trust my judgement."

Conversely, 2nd generation owners prefer their staff to work smart (staff to be efficient in their task and capable of decision making and problem solving own their own) and be creative in order to produce effective outcome. Hence, they concentrate on CSR activities which aim to enhance staff's working capabilities. Because of this, 2nd generation owners strive to build good and strong company policies in order to generate a fair working environment. This, in their perspectives, help to create commitment trust which they expect employees to be loyal to their companies and feel proud to work in the company.

"Nowadays, it is extremely easy for employees to come and go. Sometimes I can't do anything about it. When employees with potential surface, we want to be supportive of their growth in terms of their career path. So, I will train them well and make sure that they become better. In the end, it is still up to them whether they choose to stay here or not."

\section{Society}

Both generations aspire to be part of their society albeit in different manners. In their society, 1st generation owners want to generate personal connections and the ability to be able to access resources from social benefits directly while being personally satisfied. 
That is why they chose to engage in religious based activities. Their status of a moral business owner is important to them and they are satisfied when society recognises their ethical behaviours.

"I want everyone to know that I am a good person. That I have a Buddhist's heart. That is why I help to sponsor temples and events that help to spread Buddhist teachings."

By contrast, 2nd generation owners suggested that they expect good business connections from engaging in these social CSR activities and that engaging in these activities can improve their brand reputation significantly. Since many local people are potential customers, they can be perceived as a friendly business and allow them to create regular customers who are willing to support their businesses.

"A lot of my customers are people from this town and nearby provinces. When I hold events to help the community, my company name is shown. I even get compliments about these events from my customers when they come to my shop."

\section{Business}

The business aspect addresses more of the 2nd generation's expectations since they are more business-oriented when engaging in CSR activities. They expect that customers will trust more in brand reputation and image. 1st generation only requires the trust of their customers that they can provide good products and services. 1st generation owners have worked hard in order to create trust and generate word of mouth.

"I've worked hard all my life so that my family can be stable. Of course, I have to be honest in my line of work (Jewellery). People of this town knows how hardworking I am and they come to my shop to support me for my honest work. These people then help to recommend my shop to new customers."

Customers often choose them because they have good relationship with the owners. Despite trying to gain business advantages through CSR, 2nd generation owners of fruit-processing and jewellery sectors mentioned that it is difficult for them to please customers who are closely acquainted with their parents. It is then even more crucial for them to build the brand image so that customers will trust in the brand itself and not only the figurehead of the company, especially when they plan to expand their businesses.

"I foresee a problem if this goes on longer. My customers come to our shop only to be serviced by my mom and dad. Soon my dad will retire. What will happen to the company then? Right now I am trying to build my shop's brand and awareness so that it will survive in the long run. I believe many of my competitors are facing the same problem too."

Therefore, they are even more incentivised to use CSR as a tool for brand promotion and perhaps also incentivised to formalise their CSR activities.

\section{Conclusions}

In conclusion, this exploratory study has provided insights on the differences and similarities of CSR activities among 1st and 2nd generation of Thai FRBs. It is worth to study the role and impact of CSR practices and motivations between different generations of Thai FRBs because it offers researchers a window into the role and 
contribution of owner ethics in CSR issues as well as the initial origin of CSR. It is also possible that is the disruption and transition between leadership styles that can highlight CSR practices to a far better extent than a study of "normal" business operation.

Through semi-structured interviews of 17 FRB owners from two generations, it was found that there are significant and stark similarities and differences to the origin of CSR drivers, CSR behaviours, CSR targets and activities, and CSR expectations of each generation. Values of 1st generation owners are often associated with their religious teachings, more precisely the "Law of Karma" which is philanthropic, not altruistic. Values of 2nd generation owners are passed down from the 1st generation through family culture and not the religious teachings. However, both of the drivers for their CSR activities are intrinsic and their ethics are shaped by religious teachings and culture, not by cohort effect or different education levels.

CSR behaviours are looked at in 7 aspects. 1st generation owners do not link CSR with their business and their CSR events are not formalised. They treat their employees as families. 1st generation owners are ethically motivated to conduct CSR and are often involved in one-off activities. The CSR system of 1st generation owners are generally informal and they engage in CSR for personal satisfaction. On the other hand, 2nd generation owners engage in CSR more formally and they also link the CSR to their business strategies more. They also have a hierarchical management style with their employees. Interestingly, distance between staff within a company is created by hierarchy and by formalisation and standardisation. CSR engagement, in their views, can be seen as a tool to increase profitability in the long-run and so they conduct CSR systematically. The workplace under 2nd generation owners are more procedural to reduce judgemental bias. It appears that 1st generation owners engage in CSR for intrinsic and ethical reasons and 2nd generation owners engage in CSR for more strategic and operational reasons.

Both generation of owners have 2 main beneficiaries for their CSR engagement namely their employees and society as defined as the place they live in. As the most important factors of businesses, owners aspire to satisfy their employees. Yet, they have different measures in doing so. 1st generation owners emphasise providing financial aid to employees in need in order to create loyalty to them as persons. 2nd generation owners focus on developing their employees into better people through training programmes. 1st generation owners prefer religious activities for social betterment because they value their names to be known locally. 2nd generation owners prefer local sponsorship in order to create good brand reputation for their company. Lastly, 1st and 2nd generation owners have different expectations from engagement in their chosen CSR activities. While 1st generation owners expect their employees and surrounding society to trust them as a figure, 2nd generation owners expect these people to trust and have better impression of the company as a brand for long-term benefits.

It cannot be denied that 1st and 2nd generation FRBs operate from different bases where 2nd generation are often much more established as an organisation than the 1st generation. There can be other variables, such as company size, sector, degree of formalisation, other than their respective generations that may affect their CSR attributes. However, it can be seen by comparing FRBs from different generation, but with similar company sizes, that their CSR behaviours are still different. Therefore, it can be concluded that the effects that these owners are of different FRB generation is greater than 
the effect of company size and degree of formalisation. Although 1st generation owners from different FRB sectors suggested that their CSR activities are similar, and 2nd generation owners suggest that their CSR activities are similar across sectors, further research data had been collected from these FRB owners' employees which suggest there are differences across sectors between the two generations. Moreover, since there are clear differences between 1st and 2nd generation CSR activities, the changes must happen at some point between the transition process.

Even though the difference between the generations is stark, it is not clear what the reason for this is. Different levels of education between 1st and 2nd generation owners may be the reason for the change in business management structure, leading to different CSR approaches. There could also be events in the history of the respective owners that causes the difference. Further research is needed to find out answers to these questions. Nevertheless, CSR does exist in Thai FRBs although it may not be formal or documented, especially during the founders' era. It has been embedded in the cultural roots of each family and carried on through employees. Through time, these CSR activities change according to their carrier, but the essence of family culture can still be recognised.

\section{Abbreviations}

CSR: Corporate social responsibility; FRBs: Family-run businesses; MNCs: Multinational companies; SMEs: Small and medium enterprises

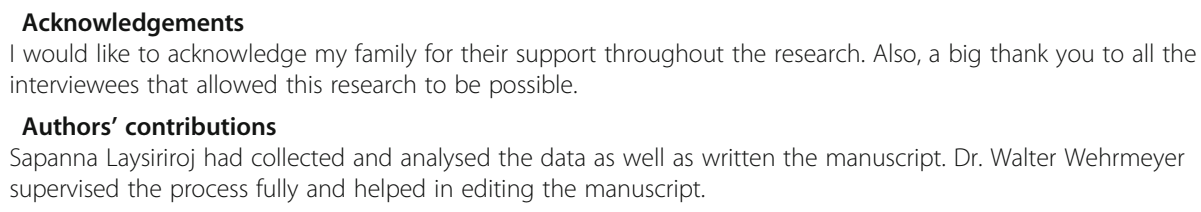

Availability of data and materials

Please contact the author for availability of data.

Competing interests

The authors declare that they have no competing interests.

Received: 16 January 2019 Accepted: 16 December 2019

Published online: 16 January 2020

\section{References}

Aronson, J., (1995). A pragmatic view of thematic analysis. The qualitative report, 2(1), pp.1-3

Astrachan JH, Klein SB, Smyrnios KX (2002) The F-PEC scale of family influence: a proposal for solving the family business definition problem1. Fam Bus Rev 15(1):45-58

Astrachan JH, Shanker MC (2003) Family businesses' contribution to the US economy: a closer look. Fam Bus Rev 16(3):211219

Brammer S, Williams G, Zinkin J (2007) Religion and attitudes to corporate social responsibility in a large cross-country sample. J Bus Ethics 71(3):229-243

Carroll AB (1979) A three-dimensional conceptual model of corporate performance. Acad Manag Rev 4(4):497-505

Carroll AB (1991) The pyramid of corporate social responsibility: toward the moral management of organizational stakeholders. Business horizons 34(4):39-48

Chapple W, Moon J (2005) Corporate social responsibility (CSR) in Asia: a seven-country study of CSR web site reporting. Bus Soc 44(4):415-441

Chrisman JJ, Chua JH, Sharma P (2005) Trends and directions in the development of a strategic management theory of the family firm. Entrepreneurship theory and practice 29(5):555-576 
Chua JH, Chrisman JJ, Sharma P (1999) Defining the family business by behavior. Entrepreneurship theory and practice 23(4): 19-39

Dahlsrud A (2008) How corporate social responsibility is defined: an analysis of 37 definitions. Corp Soc Responsib Environ Manag 15(1):1-13

Davis K, Frederick WC (1984) Business and society: Management, public policy, ethics: McGraw-Hill Companies

Dobers P, Halme M (2009) Corporate social responsibility and developing countries. Corp Soc Responsib Environ Manag 16(5):237-249

Eua-anant, P., Ayuwat, D. and Promphakping, B., (2011). Relations between positive impacts of CSR, external support, CSR knowledge and the degree of CSR practices in Thai small and medium enterprises. The International Business \& Economics Research Journal (online), 10(11), p.17

Freeman RE (2010) Strategic management: A stakeholder approach: Cambridge University press

Friedman BA (2009) Human resource management role implications for corporate reputation. Corp Reput Rev 12(3):229-244 Greiner, LE (1997): Evolution and Revolut410ion as Organizations Grow: A company's past has clues for management that are critical to future success. Family Business Review, 10(4):397-409.

Jamali D, Mirshak R (2007) Corporate social responsibility (CSR): theory and practice in a developing country context. J Bus Ethics 72(3):243-262

Jamali D, Zanhour M, Keshishian T (2009) Peculiar strengths and relational attributes of SMEs in the context of CSR. J Bus Ethics 87(3):355-377

Jenkins H (2004) A critique of conventional CSR theory: an SME perspective. J Gen Manag 29(4):37-57

Lantos, G.P. (2001: the Boundaries of Corporate Social Responsibility. J Consum Mark 18(7):595-632.

Laysiriroj, S; Wehrmeyer, W; Murphy, R (2017): Differences in CSR Activities And Perceptions Between Managers And ShopFloor Workers In Family-Run Businesses In Eastern Thailand; Proceedings of The Sixth International Conferences On Advances In Economics, Social Science and Human Behaviour Study - ESSHBS 2017, Bangkok, Thailand, $26-26$ Feb 2017 https://doi.org/10.15224/978-1-63248-120-7-43.

Lee EM, Park S-Y, Lee HJ (2013) Employee perception of CSR activities: its antecedents and consequences. J Bus Res 66(10): $1716-1724$

Looser S, Wehrmeyer W (2016) Ethics of the firm, for the firm or in the firm? Purpose of extrinsic and intrinsic CSR in Switzerland. Social Responsibility Journal 12(3):545-570

Mackey A, Gass S (2005) Second language research methodology and design. Lawrence Erlbaum, Mahwah, N.

Moran H (2006) A grounded theory on helping behavior and its shaping factors. The Grounded Theory Review: An International Journal 5(2/3):103-115

Onozawa N (2013) A study of CSR in Thailand (I): awareness and practice. Bulletin of Tsukuba Gakuin University 13(24):13-24

Perrini F, Minoja M (2008) Strategizing corporate social responsibility: evidence from an Italian medium-sized, family-owned company. Business Ethics: A European Review 17(1):47-63

Saunders M, Lewis P, Thornhill A (2009) Research methods for business students (5th edn). Pearson Education, p 240

Sims RL, Keon TL (1997) Ethical work climate as a factor in the development of person-organization fit. J Bus Ethics 16(11): 1095-1105

Uriarte F (2008) Corporate social responsibility in ASEAN. In: Paper presented at the LCF CSR conference Retrieved 22 February 2017, from http://www.aseanfoundation.org/documents/brochure/AF_CSR_Booklet.pdf

Vaismoradi M, Turunen H, Bondas T (2013) Content analysis and thematic analysis: implications for conducting a qualitative descriptive study. Nursing \& health sciences 15(3):398-405

Visser W (2008) Corporate social responsibility in developing countries The Oxford handbook of corporate social responsibility

Ward, JL (1987): Keeping the Family Business Healthy: How to Plan for Continuing Growth, Profitability, and Family Leadership, Palgrave https://doi.org/10.1057/9780230116122.

Zaharia, R.M., (2011). Employees' expectations from CSR: the case of master students. In 3rd International Conference on Advanced Management Science, IPEDR (Vol. 19)

\section{Publisher's Note}

Springer Nature remains neutral with regard to jurisdictional claims in published maps and institutional affiliations.

\section{Submit your manuscript to a SpringerOpen ${ }^{\circ}$ journal and benefit from:}

- Convenient online submission

- Rigorous peer review

- Open access: articles freely available online

- High visibility within the field

- Retaining the copyright to your article

Submit your next manuscript at $>$ springeropen.com 